\title{
MICROMETEOROLOGICAL MEASUREMENTS IN AMAZON FOREST DURING GTE/ABLE 2A MISSION
}

Y. Viswanadham, L. C. B. Molion, A. O. Manzi, L. D. A. Sá, and V. P. Silva Filho

Instituto de Pesquisas Espacials, Secretaria Especial de

Ciência e Tecnologia da Presidēncia da Repüblica, São José dos Campos, Brazil

$$
\text { R. G. B. Andrē }
$$

Universidade Estadual Paulista, Jaboticaba1, Brazil

$$
\text { J. L. M. Nogueira and R. C. dos Santos }
$$

Instituto de Pesquisas Espaciais, Secretaria Especial de

Ciēncia e Tecnologia da Presidência da Repüblica, São José dos Campos, Brazil

Abstract. As part of the Global Tropospheric Experiment/Amazon Boundary Layer Experiment 2A, micrometeorological measurements were made using a $45 \mathrm{~m}$ scaffolding tower located in the Ducke Reserve Forest site $\left(2057^{\prime} \mathrm{s}, 59057^{\prime} \mathrm{W}\right) 26 \mathrm{~km}$ northeast of Manaus, Amazonas, Brazil. We report the daily variation within and above the forest of several meteorological parameters such as temperature, humidity, winds, radiation exchange, and energy partition into latent and sensible heat fluxes. Estimates of eddy diffusivity coefficients for momentum, heat, and water vapor were made using the observed profiles. These results provide information on the physical processes involved in the exchange of momentum, heat, and water vapor between the forest and the air layer above. To account for the anomalies in eddy diffusivities, a brief discussion is presented based on turbulent transport processes.

\section{Introduction}

The motive for studying turbulent flow in the plant environment is to understand the processes governing momentum, heat, and mass exchange between the atmosphere and the biologically active canopy. This exchange regulates the microclimate in which plants grow, provides them with carbon dioxide $\left(\mathrm{CO}_{2}\right)$ for photosynthesis, and removes the water vapor provided in transpiration. An understanding of its mechanisms is essential for a variety of applications in various allied fields (e.g., biology, hydrology, agriculture, forestry, and atmospheric chemistry). The study of turbulence in and above plant canopies is also relevant to broader questions concerning the global balances of $\mathrm{CO}_{2}$ and nitrogen $\left(\mathrm{N}_{2}\right)$. Because of these strong and diverse practical motives, a great deal of discussion is presented by Thom [1975], Raupach [1979, 1987], Shuttleworth and Calder [1979], Shuttleworth et a1. [1984a, b], Raupach and Thom [1981], de Bruin [1983], Raupach and Legg [1984], McNaughton and Spriggs [1986], Viswanadham et a1.

Copyright 1990 by the American Geophysical Union.

Paper number 90JD00600.

0148-0227/90/90JD-00600\$05.00 [1987a, b], Meyers and Paw U [1987], Sä et al. [1988], Fitzjarrald et a1. [1988], Shuttleworth [1988a], and Naot and Mahrer [1989].

Whether tropical forests act as a source or sink of minor gaseous atmospheric constituents has not yet been thoroughly investigated. In particular, a tropical forest absorbs more solar radiation and generates higher evapotranspiration flux than a temperate forest. Turbulence is also high over a tropical forest because of very high daytime convection and the large aerodynamic roughness in comparison with other surfaces. When this rough forest surface interacts with the airflow above and within it, momentum is absorbed from the flow by form and skin-friction drag on elements. Heat and other scalar properties, like the minor constituents of atmospheric air, are exchanged between the flow and the elements. Momentum and scalar properties are transported vertically by turbulent diffusion. The elements of the canopy generate turbulent wakes, which convert the mean kinetic energy of the flow into turbulent kinetic energy at length scales characteristic of the elements [Thom, 1975, Raupach and Thom, 1981]. Yet scalars are predominantly transferred by usual larger events.

The trace gases carbon monoxide ( $\mathrm{C0}), \mathrm{CO}_{2}$, methane $\left(\mathrm{CH}_{4}\right)$, and ozone $\left(\mathrm{O}_{3}\right)$, including water vapor, are important to the energy balance of the Earth and, consequently, to the global climate, due to the so-called "greenhouse effect." Major changes in the global concentration of these gases, through increasing human activities in tropical regions, are likely to introduce severe changes in the climate. As part of the Global Tropospheric Experiment/Amazon Boundary Layer Experiment (GTE/ABLE 2A), various measurements were conducted in the Amazon region of Brazil during July and August 1985 [see Harriss et al., 1988]. This paper reports some results from the micrometeorological experiments conducted during the same period in the central Amazon Forest to assess the physical conditions of the atmospheric surface layer.

\section{Experimental Site and Measurements}

The area selected was in the central Amazon Forest. Measurements were made using a 45 in 
scaffolding tower in the Ducke Reserve Forest site $\left(2^{0} 57^{\prime} \mathrm{S}, 59^{0} 57^{\prime} \mathrm{W}\right)$, property of the Instituto Nacional de Pesquisas da Amazōnia (INPA), $26 \mathrm{~km}$ northeast of Manaus, Amazonas, Brazil. There are two broad forest classes in Amazonas: "igapó," or flooded forest, and dryland or "terra firme" forest, which is never flooded. The Ducke Reserve Forest (DRF) is of the latter class. Takeuchi [1961] presented a description of the central Amazonas forest in which more than $40 \%$ of the trees belonged to the families Leguminosae (Aldina heterophylla Spr. ex Benth.) and Sapotaceae (Glycoxylom inophyllum Mart. ex Miq.). Near the tower, tree heights vary from 24 to $42 \mathrm{~m}$ [see Moore and Fisch, 1986; Sá et al., 1988]; the average forest canopy height was considered to be about $35 \mathrm{~m}$. Plant density is high, up to 3000 stems per hectare, but less than $10 \%$ of trees have girths of $0.2 \mathrm{~m}$ or more. There are no obvious substories. The middle and lower parts of the canopy are made up of numerous but individually smaller plants. Ground level vegetation is scarce. The canopy leaf area index of the DRF was about $5.01 \mathrm{~m}^{2} \mathrm{~m}^{-2}$ [Sellers et al., 1989].

Nearly $85 \%$ of the soils examined at this site are the yellow laterite soils ranging from very heavy to light texture. The remaining $15 \%$ are of hydromorphic types. The physical properties of these soils are good for penetration of water and soil heat fluxes, but the chemical properties are quite unfavorable for agriculture [Instituto de Pesquisas e Experimentação Agropecuäria do Norte, 1969].

A survey of the climate of the Amazonas basin is a difficult task. The network of stations is very meager in vast regions of the Amazonas Basin and renders difficult the comprehension of weather conditions necessary for an adequate interpretation of the climate. The general climate of the region is described by Ratisbona [1976]; the atmospheric dynamics and the interactions between convective and large-scale motions are found in the works by Molion [1987] and Paegle [1987]. Some other details are presented elsewhere [Sä et al., 1988].

Analysis of stemflow data [see Lloyd and Marques Filho, 1988] indicates that, although certain tree species are capable of yielding high stemflow, the overall contribution to soll water from down the tree trunks is small. The values of throughfall and stemflow, as a percentage of gross rainfall obtained in the experimental area (DRF), were $91( \pm 2) \%$ for throughfall and $1.8( \pm 1) \%$ for stemflow over the 2 year study period. These values are consistent with previous measurements in this type and region of Amazonian rain forest, if the size of the errors is taken into account.

Over the 2 year study period [see

Shuttleworth, 1988a], approximately $10 \%$ of rainfall was intercepted by the forest canopy, and this accounted for $20-25 \%$ of the evaporation. The remainder occurred as transpiration from the trees. Over this period, about one half of the incoming precipitation is returned to the atmosphere as evaporation, a process which requires $90 \%$ of the radiant energy input [Sá et al., 1988]. These proportions exhibit some seasonal behavior in response of the large seasonal variation in rainfall. Monthly average evaporation exceeds potential estimates by about
$10 \%$ during wet months (December to May) and fall below such estimates by at least this proportion in dry months (June to November) [Shuttleworth, 1988a]. Lloyd et a1. [1988] have mentioned that the value of the mean evaporation rate derived from the meteorological measurements is similar to those found in temperate latitudes; the value of the mean rainfall rate is almost a factor of 5 higher. It is this high rainfall rate which causes the comparatively low percentage interception loss. A given quantity of rain falling on this tropical forest will take one fifth of the time compared to the same amount of rain falling on a forest in a temperate maritime c1imate. The time for evaporation during storms and the fractional interception loss are correspondingly reduced.

The topography of the reserve is gently undulating with valleys several tens of meters deep occurring at about $300 \mathrm{~m}$ intervals. About $75 \%$ of the reserve is covered with natural forest. The topography of the canopy top is modulated by the differential growth of the vegetation. The tower is sited near the top of a broader than average ridge. The eddy correlation and profile measurements described in this paper assume that the fluxes are one-dimensional, and an adequate fetch is required for this assumption. The tower has fetches of undisturbed forest extending more than $2 \mathrm{~km}$ in most directions. A common intuitive rule among micrometeorologists was for a height/fetch ratio range of $1 / 100$ to $1 / 500$ [Bradley, 1968; Fritschen et al., 1973]. This ratio was necessary if a $90 \%$ level of shear stress adjustment was acceptable. It is derived on the basis of turbulent boundary layer theory at a rigid wall.

All radiation instruments were mounted at a height of $45 \mathrm{~m}$ at the top of an aluminium scaffolding tower. One upward facing Kipp solarimeter, two downward facing Kipp solarimeters, and two Funk-type net radiometers were used to provide the measurements of incoming solar radiation $S+(W \mathrm{~m}-2)$, reflected solar radiation $S \uparrow\left(W^{-2}\right)$, and net radiation $R\left(W^{-2}\right)$, respectively. The sensitivity of these instruments is $0.85 \mathrm{mV} / \mathrm{mW} \mathrm{cm} \mathrm{cm}^{-2}$. These were mounted perfectly level at the end of $3.5-\mathrm{m}$ booms orientated approximately $30^{\circ}$ west and $30^{\circ}$ east of north. With this orientation there was no possibility of tower shade interfering with the measurements. The mean value of two measurements was considered in the case of net and reflected radiation parameters. The measurements produced by these pairs of instruments agreed within systematic error of $3 \%$ or less: their respective mean values were used in the analysis. All the radiometers used in this experiment have been used and recalibrated over 10 years with a total change in calibration of about $1 \%$ over this time. The data were recorded by an analog-digital interface linking system with a microcomputer (Commodore 64). The processed 20-min data sets from the microcomputer are saved both on a disk and a paper printout. The digital noise in the measurements is reduced to around $1.5 \mathrm{~W} \mathrm{~m}^{-2}$.

The measurements of temperature and humidity through and above the canopy were made with aspirated, quartz crystal psychrometers manufactured by Hewlett-Packard (Figure 1). All instrumentation details of these psychrometers 


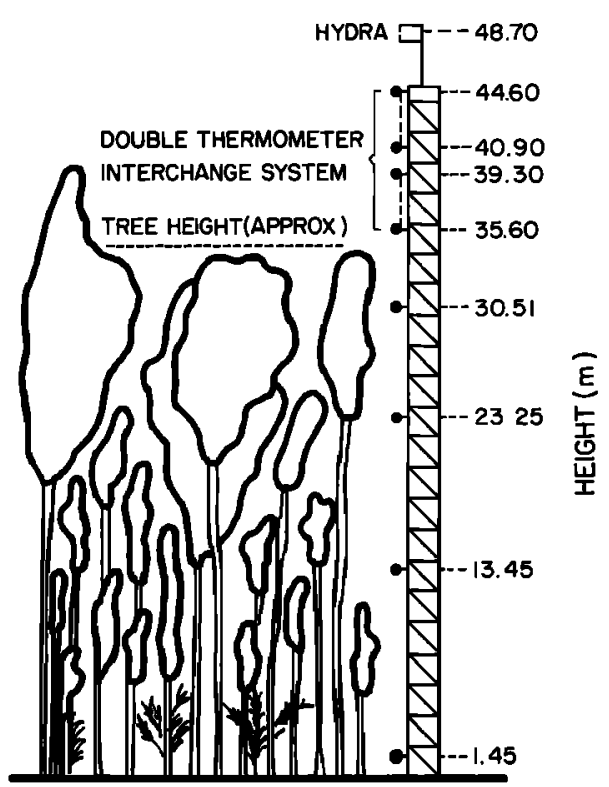

Fig. 1. Schematic diagram illustrating heights of aspirated psychrometers (black dots), the double interchange psychrometer systems, and Hydra mounted on the 45-m tower.

are presented by Gash and Stewart [1975]. It is quite difficult to measure gradients over tall vegetation with absolute instruments.

Differential measurement techniques are a more credible means of measuring these gradients. So, above the canopy a double thermometer interchanging system (i.e., differential psychrometers system, Figure 1) was used similar to that described by McNeil and Shuttleworth [1975]. This system provides accurate measurements of the temperature and humidity gradients by regularly interchanging and monitoring the psychrometers with a PET microcomputer, which was installed in an airconditioned shed at the base of the tower. The measurements represent the spatial average at each level to an accuracy of $0.02^{\circ} \mathrm{C}$ in temperature and $0.2 \mathrm{~g} \mathrm{kg-1}$ in humidity.

Winds were measured at 12 levels (i.e., 1.5, $2.9,13.5,23.3,30.5,35.6,37.5,39.3,41.0$, $42.8,44.7$ and $48.7 \mathrm{~m})$ with anemometers of the type modified by Sheppard [Stewart and Thom, 1973]. They are subject to stalling errors for speeds lower than $0.2 \mathrm{~m} \mathrm{~s}^{-1}$ and to overspeeding, which was estimated to be $2-5 \%$ increase at wind speeds around $5 \mathrm{~m} \mathrm{~s}^{-1}$. The profile data sets (wind, temperature, and humidity) were originally obtained over 20-min intervals. Three consecutive 20-min interval profiles were used to obtain 1-hour mean profiles which were analyzed for this study.

Progress in sensor development has been complemented with further advances in the implementation of real-time digital processing into eddy correlation systems. Information on such eddy correlation systems is given elsewhere [Campe11 and Unsworth, 1979; Shuttleworth et al., 1982, 1988; Coppin and Taylor, 1983; Lloyd et al., 1984; Moore, 1986; Shuttleworth, 1988b]. Moore [1986] commented that it is impossible to design even a near-perfect sensor array required to implement the technique; compromise between sensor size and separation will always be necessary, while the bandwidth of sensors and data acquisition systems, although improving, will remain limited. In practice, the errors in flux and variance tend to occur preferentially at particular times of a day. They are, of course, severe in periods of most rapid change in the morning and evening.

The momentum, sensible heat, and evaporation fluxes were measured with a "Hydra," a batterypowered eddy correlation flux measuring device developed by the Institute of Hydrology, Wallingford, England. The instrument was mounted on a pole above the tower at a height of $48.4 \mathrm{~m}$. Further details about the measurements of Hydra are described by Shuttleworth et al. [1982] and Sá et al. [1988]. The Hydra system cannot provide reliable measurements during rain when the hygrometer, sonic anemometer and thermocouple are wet, and the sensors generally take about an hour to dry out after a rain storm. Therefore the hourly Hydra data sets for nonrainy days were selected for analysis.

Previous studies [e.g., Shuttleworth et al., 1982, 1988; Lloyd et al., 1984; Moore, 1986; Shuttleworth, 1988b] have presented information of an eddy correlation system (Hydra) and the investigation of errors in the measurements of flux and variance of an atmospheric entity given by this system which employs real-time analysis, when there is real or apparent change in its measured concentration. The major errors in the eddy correlation measurement can be identified as (1) calibration errors, probably the largest of which is about $\pm 5 \%$ in the vertical wind speed. This includes uncertainty in its effective calibration due to such effects as cosine errors and self-sheltering of the transducers,

(2) h1gh-frequency loss resulting from the inadequate time response of the sensors,

(3) low-frequency loss due to inadequate sampling of the long-period eddies, i.e., an inappropriate time constant in the filter used to derive the moving average, and (4) underestimation of the fluxes resulting from the physical separation of the sensors, and sheltering of the sensors when the instrument is badly exposed, 1.e., the wind is blowing along the instrument rather than through it.

The original Mark 1 Hydra was used to measure fluxes over a stand of Corsican Pine forest adjacent to Berner's Heath near Thetford in East Anglia, England, and over the Amazonian rain forest in Brazil. Energy balance tests over these forests showed that the instrument performed satisfactorily, provided it was well exposed to the wind. The detrimental effects of large sensor separation and size are at a minimum when operating in the large-scale turbulence over forest. Moreover, the restricted angular acceptance of the Mark 1 Hydra was of little significance in the Amazonian study, since the wind direction there is consistently from the east [Shuttleworth et al., 1988].

Moore's [1986] analysis has shown that the arrangement of the prototype version of the Hydra could lead to flux loss in certain conditions, although in the case of measurements over tropical forest, such losses were small, of the order of 2 to $7 \%$ for sensible and latent heat and momentum fluxes. Moore [1986] also mentioned that 
these corrections are typically less than $10 \%$ but can be important and may account for up to $30 \%$ of measurements from some instrumental systems where atmospheric conditions are extreme or when exposure of sensors is not ideal. The Hydrologic Atmospheric Pilot Experiment (HAPEX) results [see Shuttleworth et al., 1988] gave good agreement between the magnitude and timing of fluxes measured with the Mark 1 Hydra and other sensors, though the Hydra can underestimate the flux by up to $9 \%$ or overestimate it by up to $3 \%$. Day-to-day variations in this order are a common feature in the Hydra data. Although some of this apparently haphazard variation is no doubt real, associated with different instrument positions and changing wind direction (and fetch), some may be of instrumental origin. Therefore comparisons between the integrated energy fluxes measured by the Hydra and the daily integral of measured net radiation suggest a possible systematic error, optimistically underestimated as $5 \%$ and pessimistically as $10 \%$ in each of the measured energy fluxes.

\section{Radiation and Energy Balances}

The radiation balance for the active canopy surface is written as

$$
\mathrm{R}=\mathrm{S} \downarrow-\mathrm{S} \uparrow-\mathrm{L} \uparrow+\mathrm{L} \downarrow-\mathrm{RL} \downarrow
$$

where $L \uparrow$ is the longwave radiation emitted by the surface and $R L \downarrow$ is the reflected downward longwave radiation. Using the definition of surface albedo $(a=S \uparrow / S \downarrow)$, emissivity $(E)$ and the Stefan-Boltzmann law, (1) is rewritten as

$$
R=(1-a) S \downarrow-\varepsilon \sigma T_{S}^{4}+L \downarrow-(1-\varepsilon) L \downarrow
$$

where $\sigma$ is the Stefan-Boltzmann constant and $T_{S}$ is the surface temperature. The emissivity of natural forests usually lies between 0.95 and 0.98 ; so the last term in (2) may be neglected. The longwave components are particularly sensitive to error, since they are calculated as a combination of several measured fluxes. The net radiation measurement at a single location may present an error of about 5\% [McNeil and Shuttleworth, 1975].

Generally, it is difficult to get clear days having similar weather conditions at equatorial stations. Fifteen typical days with quasi-simila weather are still selected for analysis. The average diurnal variation of shortwave, net, and net longwave radiation components are shown in Figure 2, for hourly averaged data of 15 days. On the average, $S \downarrow$ peaks before noon and falls slightly in the beginning of the afternoon, probably due to increasing cloudiness.

Instantaneous values of $S \downarrow$ exceeded $1000 \mathrm{~W} \mathrm{~m}^{-2}$ at times, but hourly average values of $500-700 \mathrm{~W} \mathrm{~m}^{-2}$ were more common. Average albedo values were about $13 \%$, which agrees with values reported by Shuttleworth et a1. [1984b] and Viswanadham et a1. [1987a] for the same site, and those reported for other tropical forests [Oguntoyinbo, 1970; Pinker et al., 1980]. During the daytime, $R$ is

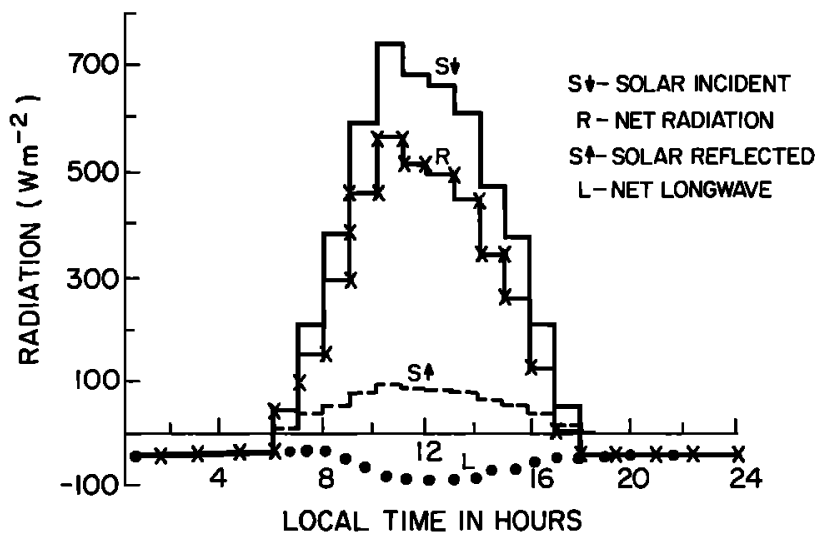

Fig. 2. The mean values of radiation components above the canopy of an Amazonian rain forest for 15 selected days.

dominated primarily by shortwave radiative exchanges, and the reflection coefficient governs the net receipt of $\mathrm{S} \downarrow$. Around midday the average net radiation was about $300 \mathrm{~W} \mathrm{~m}^{-2}$, but sometimes exceeded $800 \mathrm{~W} \mathrm{~m}^{-2}$, and through the night was rather constant with values around $-40 \mathrm{~W} \mathrm{~m}^{-2}$. At night, $R$ is made up of longwave radiation fluxes exclusively, whose surface losses are controlled by the surface temperature and emissivity. The net longwave losses were about $-70 \mathrm{~W} \mathrm{~m}^{-2}$ during the day and equal to net radiation during the night.

The available energy may be defined as

$$
A=\lambda E+H=R-G-S-P
$$

where $\lambda E$ and $H$ are the latent and sensible heats of air, respectively, $G$ is the heat into the forest floor; $S$ is the change in total heat content of the forest air, water vapor, and biomass; and $\mathrm{P}$ is energy used for other processes such as photosynthesis and photochemical reactions. All quantities are given in $\mathrm{W} \mathrm{m}^{-2}$. Generally $P$ is said to be less than $3 \%$ of net radiation [Jarvis et al., 1976] and is disregarded. Spittlehouse and Black [1980] discussed the difficulty in estimating $G$ and $S$ for forests. They claim that for periods around sunrise and sunset, $(G+S)$ is less than $5 \%$ of the net radiation flux, so that even a $50 \%$ error in this sum would result in a minor error in evaluating the available energy. The previous work of Shuttleworth et al. [1984b] for the same site reported a ground heat flux of $4 \mathrm{~W} \mathrm{~m}^{-2}$ entering the soil during the day and leaving it during the night. This value is typically less than $1 \%$ of net radiation for dense forest and may also be neglected.

Generally, the diurnal change in heat storage (S) will cause $R$ to overestimate available energy during the morning and early afternoon, and underestimate during the late afternoon and night. Moore and Fisch [1986] estimated S on a daily basis and found values between 3 and $5 \%$ of $R$. They also obtained $S$ on overcast days with rainfall and noticed $S$ occasionally in excess of $10 \%$ of $R$. The results of Moore and Fisch [1986] are in agreement with the observations of 
McCaughey [1985], and Hicks and McMillen [1988]. Hicks and McMillen [1988] mentioned that there is considerable uncertainty associated with the determination of $\mathrm{S}$, since it is computed as a small residual among several imperfectly measured quantities. They demonstrated the possible consequences of neglecting $S$ or, alternatively, of applying the first-order correction represented by the assumption that

$\mathrm{S} \cong \mathrm{bR}$

In (4), Hicks and McMillen [1988] assumed a constant value of $b=0.1$. For the Ducke Reserve Forest site a value of $b=0.042$ is obtained from Figure 4 of Moore and Fisch [1986]. Equation (4) can be utilized to compute $S$ values from measurements of $R$.

The Hydra data sets were only available on some days during July-August 1985. Figure 3 presents fluxes of net radiation, sensible heat, latent heat, and heat storage (obtained from (4)) for the 10 fine days considered in this analysis. There is a fairly constant partition of the available energy during daylight hours as latent and sensible heat, of ten some sustained evaporation into the early evening, and outgoing radiation of the order of 40 to $50 \mathrm{~W} \mathrm{~m}^{-2}$ as the forest cools during the night. The suppression of turbulent interaction between the forest and the atmosphere at night, typified by the low energy fluxes, is a feature of the data and applies to a11 the turbulence variables. The data in Figure 3 do not satisfy energy balance at night. This may be due to an overestimation of positive $\lambda \mathrm{E}$ and an underestimation of negative $H$ by Hydra during night hours. In fact, the detailed behavior of measured turbulent fluxes at night is difficult to interpret, and it is suspected that

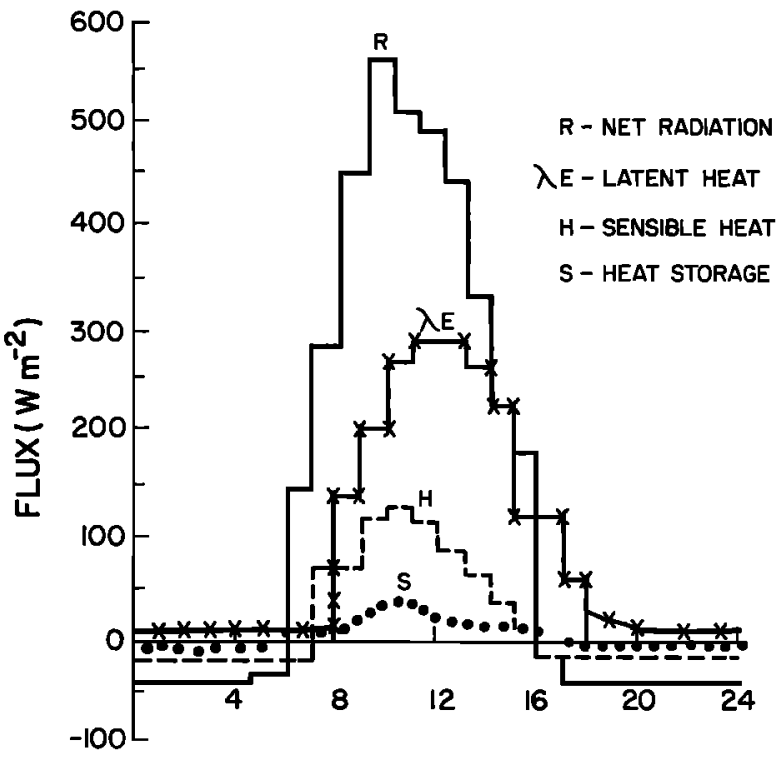

LOCAL TIME IN HOURS

Fig. 3. The mean values of net radiation, sensible and latent heat fluxes, and heat storage (from (4)) of an Amazonian rain forest for 10 selected days. hourly measurements produced by the Hydra are subject to apparently haphazard fluctuations of the order of $10 \mathrm{~W} \mathrm{~m}^{-2}$ (see discussion of Hydra measurements in section 2). This may lead to the apparent lack of energy balance closure at night in Figure 3. Heat storage within the forest canopy can be a significant portion of the energy budget for forest stands, and this is apparent in the figure. There is a loss of energy to storage in the morning as temperatures rise, and this condition reappears in the late afternoon.

From Figure 3 , it is evident that $\lambda E$ exceeds the net radiation before 0600 hours and after 1600 hours, and $\mathrm{H}$ is directed toward the forest canopy. During this period the Bowen ratio $B(=H /$ $\lambda E)$ is negative and the ratio $\lambda E / R$ is greater than unity for a period of 3 or 4 hours after 1600 hours. In nonhomogeneous terrain like the Amazonian forest, advection of hotter and/or drier air from upwind areas helps to increase $\lambda \mathrm{E}$ rates. One criterion for the identification of advective influences is that $\lambda E / R$ is consistent $1 y$ greater than unity on an hourly basis [Oke, 1979; Viswanadham and André, 1983]. The advection of drier or warmer air will also be observed with an increase of vapor pressure defictt. Sensible heat $H$ has been drawn from the air and consumed in evaporation during advection conditions. The well-defined subsidence inversions [see de Bruin, 1983; Sá et al., 1988] and the absolute values of the time rate of change of the vapour pressure deficits of the order 0.5 to 2 mbar $h^{-1}$ were observed above the canopy. All these were responsible to the results (i.e., $\lambda E>R$ ) presented in Figure 3 for afternoon hours (i.e., 1600-2000 hours) over the Amazonian forest surface.

Equation (3) is rewritten in terms of cumulative sum (i.e., 24-hour totals) of daily integrated fluxes over a period of several dry days as

$$
\Sigma \mathrm{A}=\Sigma \mathrm{R}=\Sigma(\lambda \mathrm{E}+\mathrm{H}+\mathrm{S})
$$

This equality accepted, the problem is reduced to one of partitioning the available energy among sensible, latent, and heat storage fluxes. The comparison of cumulative net radiation and the cumulative sum of $\lambda E+H+S$ for 10 days during this campaign shows a difference of -13 to $14 \%$ of the total radiant input (see Table 1). Therefore the performance in these studies was satisfactory. The Hydra measured outgoing energy fluxes (i.e., sensible and latent) which were consistent with, though in gereral the sum of these two fluxes higher than, the incoming net radiation flux as measured with commercial net radiometers. So, the technology of eddy correlation measurement has progressed such that systematic errors in surface energy measurements are now comparable to those in the particular net radiometers.

The "evaporative parameter" may be defined either as

$$
\alpha=\Sigma \lambda E / \Sigma(\lambda E+H+S)
$$

or

$$
\alpha^{\prime}=\Sigma \lambda E / \Sigma R
$$


TABLE 1. Integrated Daily Energy Fluxes for 10 Days in July-August 1985 Together With the Evaporative Fraction Defined in (6) and (7)

\begin{tabular}{|c|c|c|c|c|c|c|c|c|c|}
\hline \multirow{3}{*}{$\begin{array}{l}\text { Serial } \\
\text { No. }\end{array}$} & \multirow{3}{*}{$\begin{array}{l}\text { Date } \\
\text { in } \\
1985\end{array}$} & \multirow{3}{*}{$\begin{array}{c}\text { Solar } \\
\text { input } \\
\text { S } \downarrow\end{array}$} & \multicolumn{6}{|c|}{ Integrated Fluxes, MJ m-2 } & \multirow{3}{*}{$\begin{array}{c}\text { Percentage } \\
\text { Error }\end{array}$} \\
\hline & & & \multirow{2}{*}{$\begin{array}{c}\text { Net } \\
\text { Radiation } \\
\text { R }\end{array}$} & \multirow{2}{*}{$\begin{array}{c}\text { Latent } \\
\text { Heat } \\
\lambda E\end{array}$} & \multirow{2}{*}{$\begin{array}{c}\text { Sensible } \\
\text { Heat } \\
\text { H }\end{array}$} & \multirow{2}{*}{$\begin{array}{c}\text { Heat } \\
\text { Storage } \\
\text { S }\end{array}$} & \multicolumn{2}{|c|}{$\begin{array}{c}\text { Evaporative } \\
\text { Fraction }\end{array}$} & \\
\hline & & & & & & & $\alpha$ & $\alpha^{\prime}$ & \\
\hline 1 & July 28 & 20.06 & 11.41 & 9.40 & 1.85 & 0.47 & 0.80 & 0.83 & -2 \\
\hline 2 & July 29 & 18.74 & - & 11.70 & 0.63 & - & 0.95 & - & - \\
\hline 3 & July 31 & $20.57 *$ & $11.05 *$ & 11.49 & 0.56 & 0.46 & 0.92 & 1.04 & -13 \\
\hline 4 & Aug. 03 & $18.50 *$ & $10.73 *$ & 7.95 & 1.21 & 0.45 & 0.78 & 0.74 & 10 \\
\hline 5 & Aug. 04 & $14.19 *$ & $6.66 *$ & 5.16 & 2.12 & 0.28 & 0.65 & 0.78 & -13 \\
\hline 6 & Aug. 05 & $16.16 *$ & $7.09 *$ & 5.92 & 1.07 & 0.29 & 0.81 & 0.84 & -2 \\
\hline 7 & Aug. 06 & 18.51 & 10.88 & 6.43 & 2.42 & 0.45 & 0.69 & 0.59 & 14 \\
\hline 8 & Aug. 08 & $19.21 *$ & $8.73 *$ & 7.20 & 2.15 & 0.36 & 0.74 & 0.83 & -11 \\
\hline 9 & Aug. 18 & $19.92 *$ & $12.00 *$ & 7.90 & 2.82 & 0.50 & 0.70 & 0.66 & 6 \\
\hline 10 & Aug. 20 & 19.11 * & $10.41 *$ & 9.02 & 0.56 & 0.43 & 0.90 & 0.87 & 4 \\
\hline Mean & & 18.47 & 9.88 & 8.22 & 1.54 & 0.41 & 0.79 & 0.80 & -0.78 \\
\hline S.D. & & \pm 1.83 & \pm 1.82 & \pm 2.09 & \pm 0.80 & \pm 0.08 & \pm 0.09 & \pm 0.12 & \pm 9.48 \\
\hline
\end{tabular}

S.D., standard deviation.

* A few 20-min observations were not available due to failure of power supply and instruments. These observations are interpolated. Values of $S$ are obtained from (4). The percentage error is given by $100(R-\lambda E-H-S) / R$.

Table 1 presents the integrated daily flux of radiant energy, sensible and latent heat, and heat storage for 10 days together with the evaporative fraction defined in (6) and (7). The value of this evaporative fraction is reasonably simflar for the 10 days studied. The value $\alpha$ is smaller than $\alpha^{\prime}$ in 5 days, and vice versa in other days. These differences may be due to the storage term in (3). The presence of the physical storage term in the energy budget adds considerable complexity to the measurement. It is assumed that the cumulative net radiation over a complete day should equal the cumulative sum of the eddy correlation measurements of latent and sensible heat, and approximately estimated heat storage fluxes. It should be remembered that this check is not completely definitive in the daily cycle of a forest energy balance. So, the evaporative fraction parameter is more variable from day to day, since it includes the additional variability in this loss factor. If frequency losses (both high and low) are responsible for the failure to close the energy balance, then these will appear as roughly equal proportional errors in the Hydra measurements of both $\mathrm{H}$ and $\lambda E$. Then $\alpha$ will be correct and $\alpha^{\prime}$ will be wrong. If the error is a calibration problem (most likely in the infrared hygrometer), then $\lambda \mathrm{E}$ will be low if other fluxes are right, so again $\alpha^{\prime}$ is low and $\alpha$ is much nearer the truth. However, the implication of Table 1 is clear: the daily evaporation fraction for transpiring tropical forest for these data is around 0.8 , corresponding to a Bowen ratio, $\beta$, of 0.25 (from (6), neglecting $S$ ). This value of 0.8 is in good agreement with 0.7 of Shuttleworth et a1. [1984a] for the same site.

An hour-by-hour comparison of Hydra $\lambda \mathrm{E}$ with Bowen ratio $\lambda E\left(=R(1+\beta)^{-1}\right.$ ) would be very interesting. Unfortunately, the temperature and humidity profile data are not available from the Thermometer Interchange System (TIS).

Shuttleworth et a1. [1984a] illustrated the daily trend in a calculated for the two portions of the TIS and have compared this trend with that calculated from the eddy correlation measurements for daylight hours when relevant measurements were available. Although these results are subject to considerable experimental noise, they are in broad agreement with the TIS results, perhaps tending to favor an even lower evaporative fraction (see Figure 5 of Shuttleworth et al. [1984a]).

The Bowen ratio technique is often used to determine the partitioning of sensible and latent heat fluxes. The Bowen ratio ( $\beta$ ) values were obtained from directly measured Hydra data sets. Figure 4 presents a typical diurnal variation of $B$

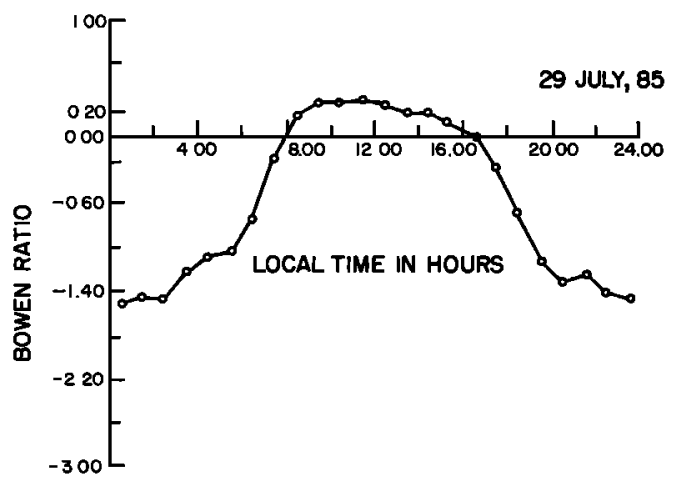

Fig. 4. Diurnal variation of Bowen ratio values for July 29, 1985, considered to be a typical dry day. 
for July 29, 1985. The diurnal $\beta$ values changed from -1.5 to 0.3 . Negative $\beta$ values merely indicate that the two fluxes have different signs. Figure 4 shows that this is common in the morning (before 0800 hours), in the evening (after 1600 hours), and at night when the sensible heat flux is downward (negative), but evaporation continues so that $\lambda E$ is away from the surface (positive). Figure 3 shows slightly positive nocturnal $\lambda E$, and negative $H$ and $S$ values. This clearly indicates that these positive nocturnal $\lambda E$ values are due to release of canopy heat storage and downward transport of sensible heat fluxes.

4. Vertical Structure of Wind, Temperature, and Humidity

Wind

The profile of the mean horizontal wind in the atmospheric surface layer over natural surfaces is generally accepted to be logarithmic in neutral stability conditions, and above tall vegetation is written as

$$
u(z)=\frac{u_{\star}}{k} \ln \left[\frac{z-d}{z_{0}}\right] \quad \frac{z}{z_{0}}>1
$$

where $u(z)$ is the mean horizontal wind at a height $z, u_{*}$ is the friction velocity, $z_{0}$ is the roughness length, $d$ is the zero plane displacement, and $\mathrm{k}(=0.4)$ is the von Kärmann constant.

The wind tunnel results of Raupach et al. [1980] show that over rough closed canopies, the logarithmic wind profile law applies only above $h+1.5 \ell$, where $h$ and $\ell$ are the height and the transverse length scale of the roughness elements, respectively. Measurements need to be made above this height (i.e., height above the underling surface $z>(h+1.5 l))$ to minimize the effect of the roughness sublayer, a region where significant vertical transport of momentum stress occurs. Information on average tree crown size is already mentioned in section 2. Taking $h=35 \mathrm{~m}$ and $\ell=D \cong 2 \mathrm{~m}$ as an upper limit for $\ell$ (where $D$ is the mean inter-element spacing), then the value for $h+1.5 \ell$ is $38 \mathrm{~m}$. So, measurements below $39 \mathrm{~m}$ were not used to compute the roughness length $z_{o}$, the zero plane diplacement $d$, and gradients from the profiles.

The stability parameter $\zeta$ is defined as [Busch, 1973]

$$
\zeta=(z-d) / L=-k g H(z-d)(1+0.075 / \beta) /\left(\rho C_{p} u_{\star}^{3} \bar{T}\right)
$$

where $\mathrm{L}$ is the Monin and Obukhov length, $\mathrm{C}_{\mathrm{p}}$ is the specific heat of air at constant pressure, $\rho$ is the density of air, $g$ is the acceleration due to gravity, and $\bar{T}$ is the average absolute temperature of the layer under consideration. As already mentioned above, winds were measured at 12 levels (see Figure 5), of which only the top five $(z>39 \mathrm{~m})$ were used in this analysis. For the data set collected in this expedition, 13 near-neutral $(-0.002 \leqq[(z-d) / L] \leqq 0.02)$ wind

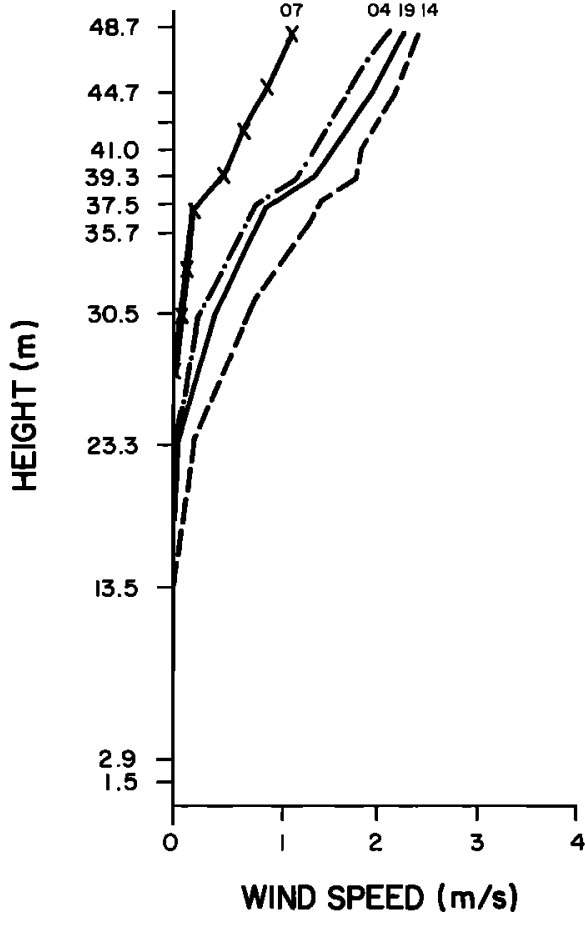

Fig. 5. Average wind speed profiles for selected local times of the day.

profiles were selected to calculate $d$ and $z_{0}$. The values of $d$ and $z_{0}$ were computed using the method outlined in Molion and Moore [1983]. At the highest level 48.7 m (about $14 \mathrm{~m}$ above the canopy), wind speeds rarely exceeded $5.0 \mathrm{~m} \mathrm{~s}^{-1}$. The estimated values of $\mathrm{d}=30.9 \pm 0.4 \mathrm{~m}$ and $\mathrm{z}_{0}=$ $2.2 \pm 0.1 \mathrm{~m}$ correspond to $(0.88 \pm 0.01) \mathrm{h}$, and $0.06 \mathrm{~h}$ for $\mathrm{h}=35 \mathrm{~m}$.

Figure 5 shows wind profiles for four different local times of day averaged during 6 days, which were not affected by large-scale disturbances. The mean wind u above 35 to $39 \mathrm{~m}$ height (i.e., in roughness sublayer) does not obey the logarithmic wind profile (Figure 5), whereas it obeys the logarithmic condition above $39 \mathrm{~m}$. Under canopy the mean horizontal wind speeds were usually below $1.0 \mathrm{~m} \mathrm{~s}^{-1}$ and there was also high turbulence intensity. In such conditions, the cup anemometers used are not accurate, so wind measurements are unreliable.

\section{Temperature and Humidity}

During this expedition, several psychrometers presented problems; it was considered preferable to maintain data collection above the canopy, at the expense of continuous humidity measurements below canopy. Figure 6 presents the diurnal variation of temperature and humidity for two consecutive days, of particular interest because they provide a comparison of measurements from a completely fine day (August 6, 1985) followed by a day in which one short rainstorm occurred. The storm occurred between 1200 and 1400 hours (local time) on the second day (August 7, 1985). Some frontal rainfall does occur at this site, but convective storms of this type are most common. Such storms are short lived, lasting 

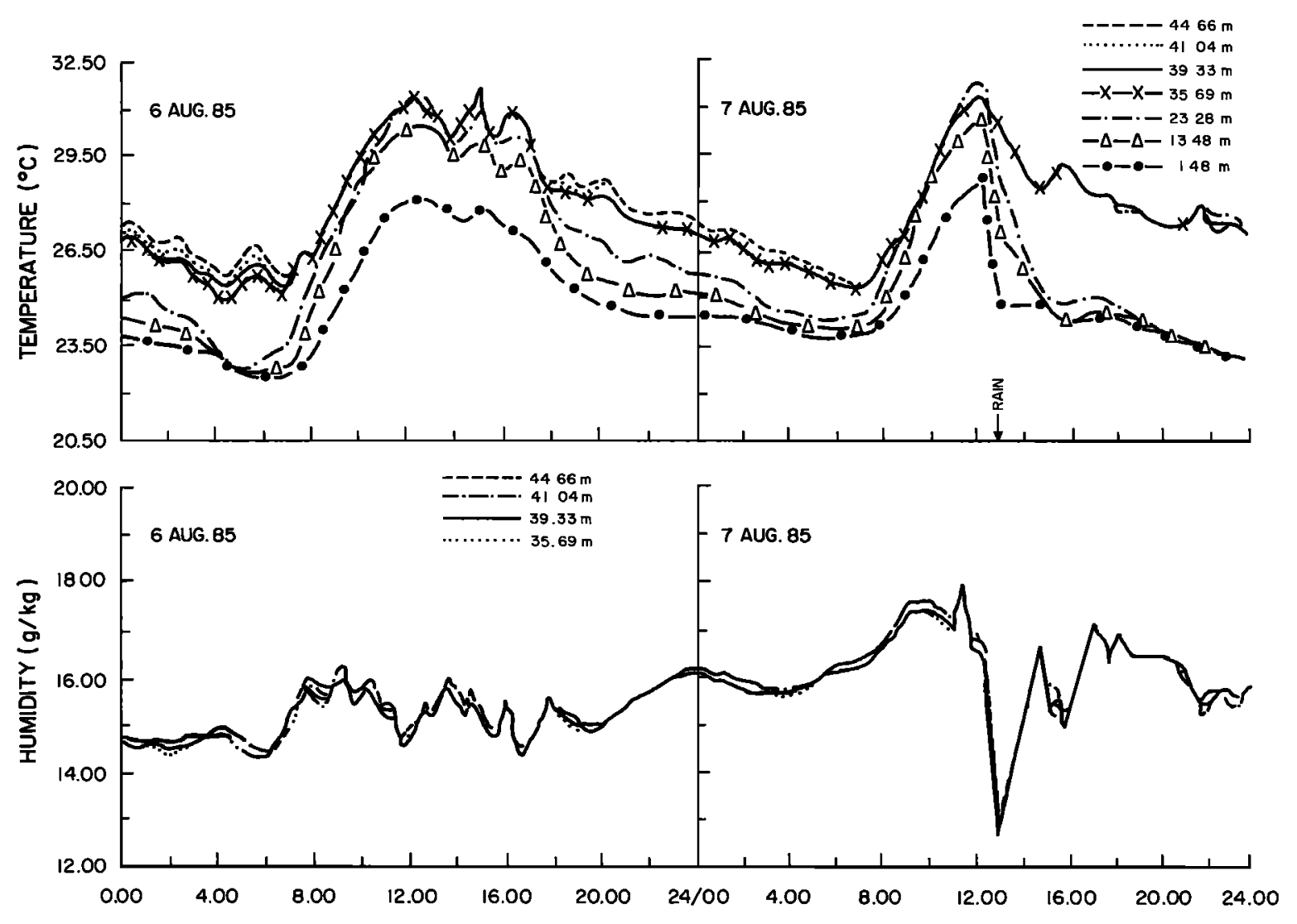

LOCAL TIME IN HOURS

Fig. 6. Daily variation of temperature and humidity within and above the forest for two consecutive days of August 1985. The arrow indicates the starting time of the rain shower.

about $30 \mathrm{~min}$, and the canopy dries rapidly afterward, usually within 2 to 3 hours. In Figure 7 , temperature and humidity are plotted as a function of height for three selected hours, 1200 on August 6, 1985, and 0000 and 1300 on August 7, 1985. Figures $7 \mathrm{a}$ and $7 \mathrm{~b}$ illustrate little variation in these profiles through the top two-thirds of the canopy during the day, and through the bottom two thirds of the canopy at night. Figure 7c shows that during and immediately after a storm there is a significant variation in temperature and humidity through the canopy.

During dry daylight hours the temperature cycle is preceded by solar radiation interception which occurs in the upper and middle portions of the canopy. Figure 6 suggests that mixing in the top two-thirds of the transpiring canopy is reasonably efficient during a day; temperature and humidity follow those of the atmosphere above to within about $1^{0} \mathrm{C}$ and $1.5 \mathrm{~g} \mathrm{~kg}^{-1}$, respectively, in dry conditions. The amplitude of the temperature cycle is about $40 \%$ of that at the top of the canopy (Figure 6). At night the temperature cycle responds to longwave radiative cooling from the bottom two-thirds of the canopy. At night the temperature of the air in the high canopy is significantly decoupled from that in the vegetation lower down (Figures 6 and $7 \mathrm{~b}$ ). No doubt this is due to the decrease in turbulent exchange as the atmosphere stability increases. In dry nighttime conditions, there is a small
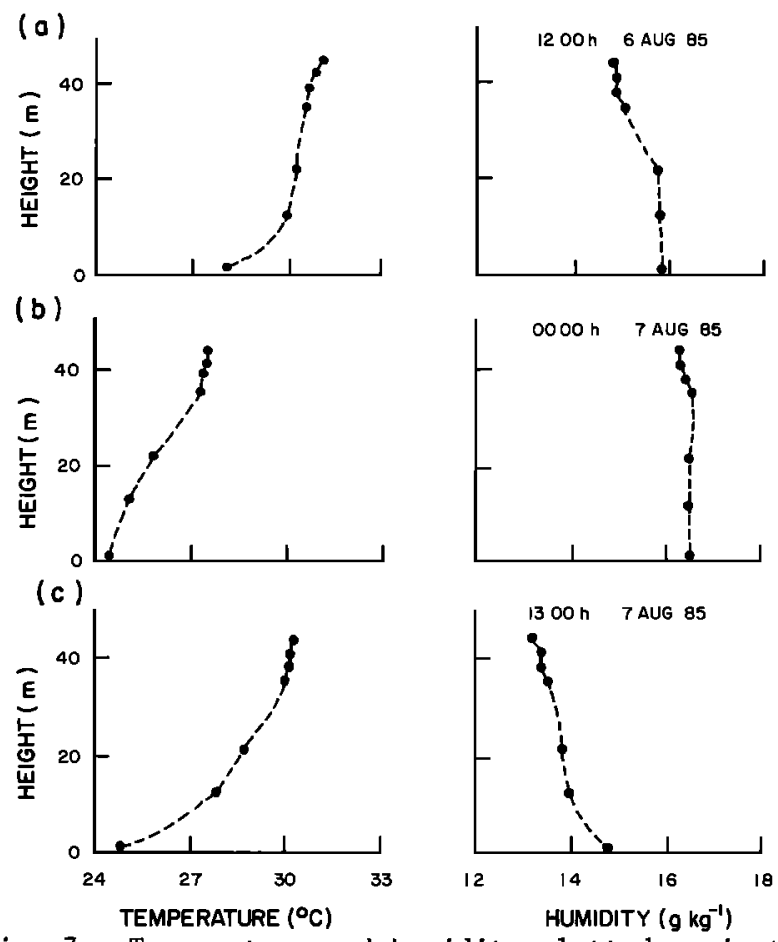

Fig. 7. Temperature and humidity plotted against height above the ground for three particular local hours (a) 1200 hours, August 6, 1985, (b) 0000 hours, August 7, 1985, and (c) 1300 hours August 7, 1985. 
(typically $0.8 \mathrm{~g} \mathrm{~kg}^{-1}$ ) variation in absolute humidity throughout the canopy (Figure $7 \mathrm{~b}$ ). The absolute humidity decreases progressively from the bottom of the canopy upward over the whole daily cycle, and in both wet and dry conditions (Figure 7). The convective storm on August 7, 1985, at about 1300 hours and its associated downdrafts provide a noticeable perturbation on this behavior. Both temperature and absolute humidity fall rapidly at all levels immediately after the storm. This may be due to the entrainment of drier air from aloft and cooling by evaporation. Some hourly profile data sets are available at this site. Unfortunately, these are not useful to evaluate the entrainment effect in detail.

\section{Eddy Transfer Coefficients}

According to the constant flux layer similarity theory [Monin and Yaglom, 1977], the dimensionless shear functions for momentum $\left(\phi_{M}\right)$, sensible heat $\left(\phi_{H}\right)$, and latent heat $\left(\phi_{W}\right)$ may be written in a general form as

$$
\frac{k(z-d)}{S_{*}} \frac{\partial S}{\partial z}=\phi_{S}(\zeta) \quad z>h
$$

where $\mathrm{S}$ may be the mean horizontal wind speed $(u)$, potential temperature $(\theta)$, and specific humidity ( $q$ ) at a height $z$ greater than the canopy height $(h) ; S_{*}$ represents any one of the scaling parameters $\mathrm{u}_{*}, \theta_{*}$, and $\mathrm{q}_{*}$ [Viswanadham, 1982], and $\phi_{S}$ may be any one of the nondimensional shear functions $\phi_{M}, \phi_{H}$, and $\phi_{W}$ (the subscripts $M, H$, and $W$ represent the parameters for momentum, heat, and water vapor transfer, respectively). The similarity theory states that the functions depend on the stability parameter $\zeta=(z-d) / L$ and the eddy diffusivities $\mathrm{K}_{\mathrm{M}}, \mathrm{K}_{\mathrm{H}}$, and $\mathrm{K}_{\mathrm{W}}$ are given by

$$
\mathrm{K}_{\mathrm{S}}=\mathrm{k}_{\mathrm{M}, \mathrm{H}, \mathrm{W}}=\frac{\mathrm{ku}_{*}(\mathrm{z}-\mathrm{d})}{\phi_{\mathrm{M}, \mathrm{H}, \mathrm{W}}}
$$

and their ratios

$$
\frac{\mathrm{K}_{\mathrm{H}}}{\mathrm{K}_{\mathrm{M}}}=\frac{\phi_{\mathrm{M}}}{\phi_{\mathrm{H}}}=\mathrm{F}_{1}(\zeta) \quad \frac{\mathrm{K}_{\mathrm{H}}}{\mathrm{K}_{\mathrm{W}}}=\frac{\phi_{\mathrm{W}}}{\phi_{\mathrm{H}}}=\mathrm{F}_{2}(\zeta)
$$

The universal functions $\phi(\zeta)$ and $F_{i}(\zeta)$ cannot be predicted by the similarity theory alone but must be supplemented with experimental work [see Viswanadham, 1982], in which fluxes of momentum, heat, and water vapor have to be measured independently.

The nondimensional functions are relatively well known in the inertial sublayer [Raupach, 1979], where they will be distinguished as $\phi_{M}^{*}(\zeta), \phi_{H}^{*}(\zeta)$, and $\phi_{W}^{*}(\zeta)$. Typical existing semiempirícal formulae are those of Dyer and Hicks [1970] for unstable conditions and Webb [1970] for stable conditions [Viswanadham, 1982]:

$\phi_{\mathrm{H}}^{*}(\zeta)=\phi_{\mathrm{W}}^{*}(\zeta)=\left[\phi_{\mathrm{M}}^{*}(\zeta)\right]^{2}=(1-16)^{-1 / 2} \quad \zeta<0$

$$
\phi_{M}^{*}(\zeta)=\phi_{H}^{*}(\zeta)=\phi_{W}^{*}(\zeta)=1+5.2 \zeta
$$

These relationships, together with an associated value of 0.4 for the von Kärman constant, are supported by the independent analyses of Paulson [1970] and Hicks [1976]. They will be used here in spite of some continuing controversy [e.g., Dyer, 1974; Yaglom, 1977; Viswanadham, 1982]. A measure of the effect of surface influences on the transfer processes is given by the ratio

$$
\gamma_{S}=\gamma_{M, H, W}=\frac{\phi_{M, H, W}^{*}}{\phi_{M, H, W}}=\frac{K_{M, H, W}}{K_{M, H, W}^{*}}
$$

which has also been considered by Garratt [1978]; $\gamma_{M}, \gamma_{H}$, and $\gamma_{W}$ are equal to the ratios of the observed turbulent diffusivities $\mathrm{K}_{M}, \mathrm{~K}_{\mathrm{H}}$, and $\mathrm{K}_{W}$, respectively, and to their expected values $K_{M}^{*}$, $\mathrm{K}_{\mathrm{H}}^{*}$, and $\mathrm{K}_{\mathrm{W}}^{*}$ in the absence of surface influences. In the roughness sublayer, dimensional analysis does not lead to simple results because the effects of roughness geometry are dynamically significant [Raupach and Legg, 1984]. An observed characteristic of this layer is that the turbulent diffusivity $\mathrm{K}_{\mathrm{S}}$ tends to be greater than the value $\mathrm{K}_{\mathrm{S}}^{*}$ expected from the inertial sublayer prediction (equation (11)). A convenient descriptor of this enhancement is the ratio $\gamma_{S}$, which is unity in the inertial sublayer and greater than unity in the roughness sublayer [Raupach, 1979; Raupach and Legg, 1984].

To determine the nondimensional functions $\phi_{\mathrm{M}, \mathrm{H}, \mathrm{W}}$ experimentally, it is necessary to measure independently the gradients of $u, \theta$, and $q$ and the fluxes of momentum, heat, and water vapor. Values of the quantities $u_{*}, \theta_{*}, q_{*}$, and the stability length $L$ (in (9)) were calculated using the Hydra data sets. Equations (9) and (10) were used to compute 1 -hour mean values of $\zeta$ and $\phi_{\mathrm{M}, \mathrm{H}, \mathrm{W}}$ for the 41.04 to $44.66 \mathrm{~m}$ layer. Quality control was applied individually to each computed value of $\phi_{\mathrm{M}}, \phi_{\mathrm{H}}$, and $\phi_{\mathrm{W}}$ to reject periods of flux nonstationarity, and also periods in which gradients (especially humidity gradients) were too small for acceptable accuracy (see Raupach [1979] for further details). Here, d is assumed to be a well-defined aerodynamic characteristic of the surface, Identical for three properties and independent of stability.

In Table 2 the data for $\phi_{\mathrm{M}}^{-1}, \phi_{\mathrm{H}}^{-1}$, and $\phi_{\mathrm{W}}^{-1}$ are presented numerically as stability-grouped averages. Inverse nondimensional functions have been given because they are directly proportional to the corresponding turbulent diffusivities (equation (11)). The inertial sublayer predictions of $\phi_{\mathrm{M}}^{*}, \phi_{\mathrm{H}}^{*}$, and $\phi_{\mathrm{W}}^{*}$ are obtained by (13). In Figure 8 , the ratios of $\gamma_{M}, \gamma_{H}$, and $\gamma_{W}$ are plotted against $\zeta$, using the stability grouped data of Table 2 .

All of the experimental values of $\phi_{\mathrm{M}}^{-1}$ are less than $\phi_{\mathrm{H}, \mathrm{M}}^{-1}$ values (Table 2). On the other hand, the maximum experimental values of $\phi_{\mathrm{H}}^{-1}$ and $\phi_{\mathrm{W}}^{-1}$ consistently depart from the corresponding inertial sublayer prediction $\left[\phi_{\mathrm{H}, \mathrm{M}}^{*}(\zeta)\right]^{-1}$ by a factor of the order of 2 . The present data set in Figure 8 implies $0.69 \leqq \gamma_{M} \leqq 1.24,0.91 \leqq \gamma_{\mathrm{H}} \leqq$ 1.67 , and $0.95 \leqq \gamma_{W} \leqq 1.95$. On the basis of Figure $8, \gamma_{M}=1$ provides a good description of the experimentally observed turbulent diffusivities for momentum with a small significant stability dependence being evident on both sides of $\zeta=0$. In the context of this 
TABLE 2. Mean Values of $\phi_{M}^{-1}, \phi_{H}^{-1}$, and $\phi_{W}^{-1}$, Averaged Into Stability Groups

\begin{tabular}{cccccc}
\hline Range of $\zeta$ & Mean $\zeta$ & $\phi_{\mathrm{M}}^{-1}$ & $\phi_{\mathrm{H}}^{-1}$ & $\phi_{\mathrm{W}}^{-1}$ \\
\hline$<-0.5$ & -0.72 & $1.33 \pm 0.31(28)$ & $4.00 \pm 0.35(26)$ & $4.34 \pm 0.39(16)$ \\
-0.5 to -0.4 & -0.43 & $1.29 \pm 0.21(24)$ & $2.94 \pm 0.41(18)$ & $3.12 \pm 0.38(14)$ \\
-0.4 to -0.2 & -0.32 & $1.23 \pm 0.19(25)$ & $2.43 \pm 0.38(22)$ & $2.85 \pm 0.45(10)$ \\
-0.2 to -0.1 & -0.16 & $1.21 \pm 0.25(23)$ & $2.12 \pm 0.32(18)$ & $2.38 \pm 0.43(9)$ \\
-0.1 to -0.01 & -0.06 & $1.16 \pm 0.28(30)$ & $1.81 \pm 0.40(28)$ & $2.04 \pm 0.55(11)$ \\
-0.01 to 0 & -0.007 & $1.14 \pm 0.22(19)$ & $1.72 \pm 0.45(17)$ & $1.92 \pm 0.53(9)$ \\
0 & to 0.01 & 0.008 & $1.13 \pm 0.26(20)$ & $1.61 \pm 0.42(16)$ & $1.69 \pm 0.58(8)$ \\
0.01 to 0.05 & 0.04 & $0.62 \pm 0.25(19)$ & $1.33 \pm 0.35(16)$ & $1.61 \pm 0.52(10)$ \\
0.05 to 0.1 & 0.08 & $0.40 \pm 0.21(18)$ & $0.64 \pm 0.26(23)$ & $0.67 \pm 0.41(9)$ \\
0.1 to 0.5 & 0.31 & $0.28 \pm 0.19(15)$ & $0.40 \pm 0.31(12)$ & $0.41 \pm 0.42(5)$ \\
$>0.5$ & 0.73 & $0.25 \pm 0.25(9)$ & $0.28 \pm 0.35(8)$ & $0.30 \pm 0.65(3)$ \\
\hline
\end{tabular}

The number of one-hour data points included in each average is shown in parentheses.

experiment, the implied small surface influence on $\phi_{\mathrm{M}}^{-1}$ on $\mathrm{K}_{\mathrm{M}}$ is not strongly significant.

For heat and water vapor, however, surface influences are highly significant in augmenting turbulent diffusivities; Figure 8 suggests that $\gamma_{\mathrm{H}}-2$ in slightly stable conditions $(0.01<\zeta<$ 0.04 ) and $\gamma_{H, W}-1.7$ in slightly unstable conditions $\left(\zeta^{\mathrm{W}}--0.01\right)$. There is a tendency for $\gamma_{H, W}$ to decrease back toward unity as conditions become more unstable. The parameter $\gamma_{H, M}$ shows an increased tendency beyond $\zeta=0.03$.

The enhancement of $\gamma_{H}$ above the Amazonian forest canopy is in accord with several atmospheric results which have found that $\gamma_{H} \cong 2$ close above forests and savannah [Garrat, 1978 ; Raupach, 1979; Raupach and Thom, 1981]. The results reported here (Table 2, Figure 8 ) and elsewhere show that the heat was passive and acted simply as a tracer, so that any other passive scalar would have behaved identically if released from the same source. This implled, in particular, that $\mathrm{K}_{\mathrm{H}} \cong \mathrm{K}_{\mathrm{W}}$, a suggestion confirmed by limited observations over forests which give $\gamma_{H} \cong \gamma_{W}$ $\cong 2$ [Raupach, 1979]. Hence, provided the source-sink distributions for heat and water vapor are similar, as they are over most closed canopies, the Bowen ratio method for measuring $\lambda E$ should be reliable even though the height of observation is usually well within the roughness sublayer.

Literature on the subject of transfer coefficient relationships in and above forests offers many diverse discussions [Raupach, 1979, 1987; Raupach et a1., 1980; Raupach and Thom, 1981; Raupach and Legg, 1984; Viswanadham et al., 1987b]. The present results (Table 2 and Figure 8) are consistent with Raupach [1979]. It is appropriate to give some of the mechanistic implications of the result that $\mathrm{K}_{\mathrm{H}}$ and $\mathrm{K}_{\mathrm{W}}$ are about twice $\mathrm{K}_{\mathrm{M}}$ over the forest, without trying to be more specific than present information permits. Supposed1y, the most probable reason for this difference in the surface layer and the layer above the forest is the ground effect on the pressure fluctuation field in the atmospheric boundary layer, as indicated by Gibson and Launder [1978]. That is, the pressure contributes to correlations which appear in the transport equations for Reynolds stress and heat flux, so that turbulent transport processes are affected not only by the stratification, but also by the modification of the fluctuating pressure field due to the presence of a wall (1.e., forest). Thom et al. [1975] pointed out that there are two mechanisms (i.e., wake diffusion and thermal seeding) which could possibly operate to increase the eddy diffusivities close to aerodynamically rough surface to values substantially in excess of those based on the Prandtl-Kärmän mixing length theory. The Thom et al. "thermal seeding" idea is just one of many possibilities for the roughness sublayer effects. Raupach et al. [1980] compared the wind tunnel results with atmospheric data, and indicated that wake diffusion may well cause some underestimation of the zero plane displacement $d$ over typical vegetated surfaces. The information presented in section 2 indicates that the measured fluxes from Hydra suffer approximately an underestimation of $10 \%$. The underestimations of the $d$ and the fluxes may permit an increase of the ratios of $\mathrm{K}_{\mathrm{H}, \mathrm{W}} / \mathrm{K}_{\mathrm{M}}$ under different stability conditions (equation (10)). Viswanadham et al. [1987b] suggested that Taylor's [1932] vorticity transfer hypothesis is more important than momentum transfer theory over the vegetated surfaces. This implies that $\mathrm{K}_{\mathrm{H}}$ is 


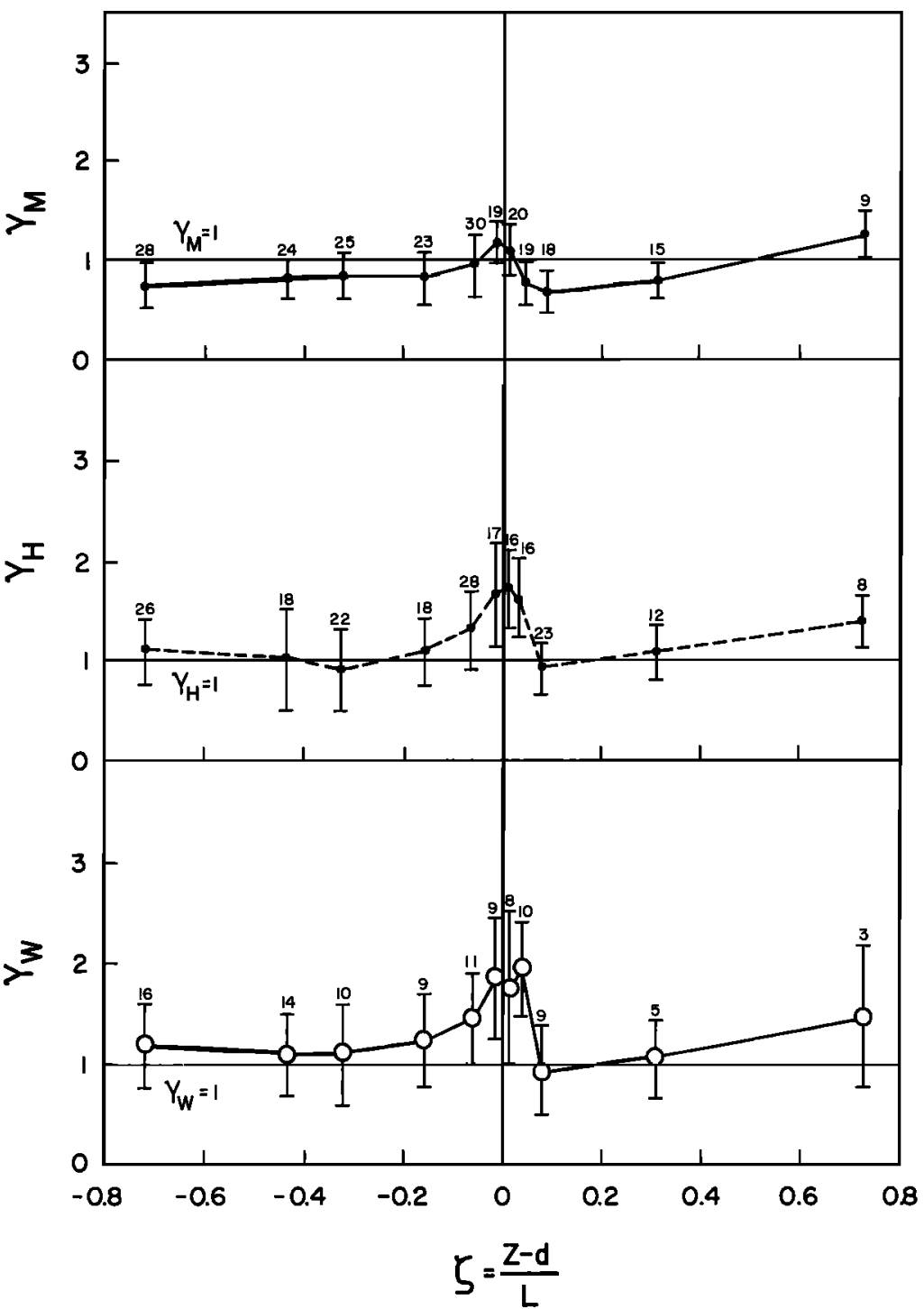

Fig. 8. The ratios $\gamma_{M}, \gamma_{H}$, and $\gamma_{W}$ defined by (14), plotted against $\zeta$.

roughly twice $\mathrm{K}_{\mathrm{M}}$ [Monin and Yaglom, 1977, P. $370]$. So these mechanisms may contribute, and the buoyant convection effects are largely responsible for the anomaly.

The three-dimensional structure of a canopy causes the onset of free convective activity to be different from those applying over the classical, infinite, uniformly heated rough surface. In the case of a canopy, free convection can be maintained by discrete heat sources or sinks, or both, the sources simply causing ascent of warmed air, and the sinks promoting exchange by displacement as air cooled near the top of the canopy descends to lower levels [Raupach, 1979]. In other words, free convection thermals could originate within the canopy in unstable conditions and emerge into the region of turbulent boundary layer flow above, where additional mixing generated would serve to enhance $K$ and reduce profile gradients. On the basis of these data, heat and water vapor are transported more efficlently than momentum immediately above the surface of the Amazon forest, especially under unstable conditions.
Problems include the effects of the roughness sublayer on $K$ and also the complete failure of $K$ theory in the canopy, which is primarily caused by the interaction of large eddies with the source-sink distributions for the various entities [see Raupach, 1987]. The reasons for the contradiction ( $\mathrm{K}_{\mathrm{H}}-2 \mathrm{~K}_{\mathrm{M}}$, near neutrality) thus remain obscure, although it may be conjectured that mechanical as well as thermal horizontal inhomogeneities become important when the surface roughness elements are discrete. Also, the problem of defining a lower height limit for the horizontally homogeneous layer over vegetation remains a subject for research.

In general, we noticed a strong similarity in the mass, energy, and exchange processes from temperate deciduous and tropical evergreen forests [Raupach, 1979; Viswanadham et al., $1987 b$ ]. It is common to assign values for $d$ and $z_{o}$ by equating them to fractions of the vegetation height h. For tall, dense, and closed canopies (h exceeds $15 \mathrm{~m}$ ), the values of $d$ are found to be in the range $0.70 \mathrm{~h}$ to $0.85 \mathrm{~h}$; whereas the values of $\mathrm{z}_{0}$ are obtained to be in the range $0.06 \mathrm{~h}$ to $0.10 \mathrm{~h}$ 
[Thom, 1975; Raupach and Thom, 1981; Jarvis and McNaughton, 1986; Viswanadham et a1., 1987b, 1989; Shuttleworth, 1988a]. Also, the midday $\lambda \mathrm{E} / \mathrm{R}$ 1s about 0.8 . We may realize that it is difficult to obtain data from tall, dense, remote tropical forests. Yet it seems that we may be able to apply principles from more accessible temperate forests to model exchange processes in the tropics.

\section{Conclusions}

The measurements and results obtained for the central Amazonas terra firme forest during the dry season of 1985 were similar to those reported in previous works [Shuttleworth et al., 1984a, b]. The average albedo was about $13 \%$; net radiation and longwave losses integrated during the 24 -hour period were $62 \%$ and $25 \%$ of the total incoming solar radiation, respectively. During dry days about $80 \%$ of the available energy was used to evaporate water, a dally average equivalent to $3.2 \mathrm{~mm}$. In a daily cycle the storage term appears to be important. When the canopy is wet, latent heat into the air is higher than the avallable energy (1.e., net radiation). In this case, the extra energy to latent heat flux is probably being supplied by the local advection and canopy storage. The range of Inferred Bowen ratios was -1.5 to 0.3 .

From the wind profiles near-neutral conditions, values of zero-plane displacement and roughness length were estimated to be $d=30.9 \pm$ $0.4 \mathrm{~m}$ and $z_{0}=2.2 \pm 0.1 \mathrm{~m}$. The temperature profiles show that during daytime, strong mixing occurs in the air layer above canopy; it appears that the bottom third below canopy undergoes a less pronounced dally cycle. The turbulent transfer coefficients for heat and water vapor were found to be approximately equal. The observed turbulent diffusivity for heat (or water vapor) in the roughness sublayer is greater than the value expected from inertial sublayer theory by a factor $\gamma_{H}$ (or $\gamma_{W}$ ), which is approximately 2 In the 41.04 to 44.66 m layer under near-neutral conditions. In general, gradient diffusion theories and the associated flux gradient relationships become progressively less reliable as one approaches a rough vegetated surface. Considerable effort is being made to find physically based, reliable models for vertical turbulent transport in these situations.

Acknowledgments. The authors would like to thank their colleagues A. O. Marques Filho, A. P. Fattori, M. Januārio, G. F. Fisch, 0. M. R. Cabral, C. A. Nobre, D. R. Fitzjarrald, B. L. Stormwind and INPA'S technicians for assistance in data collection. Financial support was provided by INPE and NASA/GTE mission management. INPA and the Brazilian Company for Agricultural Research (EMBRAPA), through its National Research Center (CNPSD), and the GTE/ABLE 2A colleagues also contributed to making this experiment successful. Thanks are due to Nilda Costa A. M. da Silva and Sueli v. Camargo Pinto for typing the manuscript, Carlos Roberto dos Santos and his group for drafting the figures, and J. C. Conforte for the data computation. The authors are grateful for the comments of the anonymous revlewers.

\section{References}

Bradley, E. F., A micrometeorological study of velocity profiles and surface drag in the region modified by a change in surface roughness, Q. J. R. Meteorol. Soc., 94, $361-379,1968$.

Busch, N. E., On the mechanics of atmospheric turbulence, in Workshop on Micrometeorology, edited by D.A Haugen, Pp. 1-65, American Meteorological Society, Boston, Mass., 1973.

Campbe11, G. S., and M. H. Unsworth, An inexpensive sonic anemometer for eddy correlation, J. App1. Meteoro1., 18, 1072-1077, 1979.

Coppin, P. A., and K. J. Taylor, A three component sonic anemometer thermometer system for general micrometeorological research, Boundary Layer Meteorol., 27, 27-42, 1983.

de Bruin, H. A. R., A model for the PriestleyTaylor parameter $\alpha$, J. Clim. Appl. Meteorol., 22, 572-578, 1983.

Dyer, A. J., A review of flux-profile relationships, Boundary Layer Meteorol., 7, $363-372,1974$.

Dyer, A. J., and B. B. Hicks, Flux gradient relationships in the constant flux layer, Q. J. R. Meteorol. Soc., 96, 715-721, 1970.

Fitzjarrald, D. R., B. L. Stormwind, G. Fisch, and 0 . M. R. Cabral, Turbulent transport observed just above the Amazon forest, J. Geophys. Res., 93, 1551-1563, 1988.

Fritschen, L. J., L. Gray, and R. Holbo, Estimating evapotranspiration from forests by meteorological and lysimetric methods, paper presented at the Symposium on Evaporation and Transpiration from Natural Terrain, AGU, San Francisco, Calif., Dec. 12, 1973.

Garratt, J. R., Flux profile relations above tall vegetation, $Q$. J. R. Meteorol. Soc., 104, $199-212,1978$.

Gash, J. H. C., and J. B. Stewart, The average surface resistance of Pine Forest derived from Bowen ratio measurements, Boundary Layer Meteorol., $8,453-464,197 \overline{5}$.

Gibson, M. M., and B. E. Launder, Ground affects on pressure fluctuations in the atmospheric boundary layer, J. Fluid Mech., 86, 491-511, 1978 .

Harriss, R. C., S. C. Wofsy, M. Garstang, E. V. Browell, L. C. B. Molion, R. J. McNeal, J. M. Hoell, Jr., R. J. Bendura, S. M. Beck, R. L. Navarro, J. T. Riley, and R. L. Snell, The Amazon Boundary Layer Experiment (ABLE 2A): Dry season, J. Geophys. Res., 93, 1351-1360,

Hicks, B. B., Wind profile relationships from the "Wangara" experiment, Q. J. R. Meteorol. Soc., $102,535-552,1976$.

Hicks, B. B., and R. T. McMillen, on the measurement of dry deposition using imperfect sensors and in non-ideal terrain, Boundary Layer Meteorol., 42, 79-94, 1988.

Instituto de Pesquisas e Experimentaçāo Agropecuäria do Norte, Os solos da ärea Manaus-Itacoatiara, Série Estudos e Ensaios, 177 pp., Belèm, Pará, Brazil, 1969.

Jarvis, P. G., and K. G. McNaughton, Stomatal control of transpiration: Scaling up from leaf to region, Adv. Ecol. Res., 15, 1-49, 1986.

Jarvis, P. G., G. B. James, and J. J. Landsberg, 
Coniferous Forest in Vegetation and the Atmosphere, vol.2, edited by J.L. Montheith, pp. 171-240, Academic, San Diego, Calif., 1976.

Lloyd, C. R., and A. de O. Marques Filho, Spatial variability of throughfall and stemflow measurements in Amazonian rain forest, Agric. For. Meteoro1., 42, 63-73, 1988.

Lloyd, C. R., W. J. Shuttleworth, J. H. C. Gash, and M. Turner, A microprocessor system for eddy-correlation, Agric. For. Meteorol., 33, 67-80, 1984.

Lloyd, C. R., J. H. C. Gash, W. J. Shuttleworth, and $\mathrm{A}$. de 0 . Marques Filho, The measurement and modelling of rainfall interception by Amazonian rain forest, Agric. For. Meteorol., 43, 277-294, 1988.

McCaughey, J. H., Energy balance storage terms in a mature mixed forest at Petawawa, Ontario: A case study, Boundary Layer Meteorol., 31 , $89-101,1985$.

McNaughton, K. G., and T. W. Spriggs, A mixedlayer model for regional evaporation, Boundary Layer Meteoro1., 34, 243-262, 1986.

McNe11, D. D., and W. J. Shuttleworth, Comparative measurements of the energy fluxes over a Pine Forest, Boundary Layer Meteorol., 9, 297-313, 1975.

Meyers, T. P., and K. T. Paw U, Modelling the plant canopy micrometeorology with higherorder closure principles, Agric. For. Meteorol., 41, 143-163, 1987.

Molion, L. C. B., On the dynamic climatology of the Amazon basin and associated rain-producing mechanism, in Geophysiology of Amazonia: Vegetation and Climate Interactions, edited by R.E. Dickinson, pp. 391-407, John Wiley, New York, 1987.

Molion, L. C. B., and C. J. Moore, Estimating the zero-plane displacement for tall vegetation using a mass conservation method, Boundary Layer Meteoro1., 26, 115-125, 1983.

Monin, A. S., and A. M. Yaglom, Statistical Fluid Mechanics: Mechanics of Turbulence I, MIT Press, Cambridge, Mass., 1977.

Moore, C. J., Frequency response corrections for eddy correlation systems, Boundary Layer Meteoro1., 37, 17-35, 1986.

Moore, C. J., and G. Fisch, Estimating heat storage in Amazonian tropical forest, Agric. For. Meteorol., 38, 147-169, 1986.

Naot, 0., and Y. Mahrer, Modeling microclimate environments: A verification study, Boundary Layer Meteorol., 46, 333-354, 1989.

Oguntoyinbo, J. S., Reflection coefficients of natural vegetation crops and urban surface in Nigeria, Q. J. R. Meteorol. Soc., 96, 430-441, 1970.

Oke, T. R., Advectively-assisted evapotranspiration from irrigated urban vegetation, Boundary Layer Meteoro1., 17, $167-173,1979$.

Paegle, J., Interaction between convective and large-scale motions over Amazonia, in Geophysiology of Amazonia: Vegetation and Climate Interactions, edited by R. E.

Dickinson, pp. 347-390, John Wiley, New York, 1987.

Paulson, C. A., The mathematical representation of wind speed and temperature profile in the unstable atmospheric surface layer, J. Appl. Meteorol., 9, 857-861, 1970.

Pinker, R. T., O. E. Thompson, and T. F. Eck, The albedo of tropical evergreen forest, Q. J. R. Meteorol. Soc., 106, 551-558, 1980.

Ratisbona, L. R., The climate of Brazil, in World Survey of Climatology, vol.12, Climate of Centra1 and South America, edited by $W$. Schwerdtfeger, Elsevier, New York, 1976.

Raupach, M. R., Anomalies in flux-gradient relationships over forest, Boundary Layer Meteorol., 16, 467-486, 1979 .

Raupach, M. R., A Lagrangian analysis of scalar transfer in vegetation canopies, Q. J. R. Meteorol. Soc., 113,107-120, 1987.

Raupach, M. R., and B. J. Legg, The uses and limitations of flux-gradient relationships in micrometeorology, Agric. Water Management, 8, 119-131, 1984.

Raupach, M. R., and A. S. Thom, Turbulence in and above plant canopies, Annu. Rev. Fluid Mech., $13,97-129,1981$.

Raupach, M. R., A. S. Thom, and I. Edwards, A wind-tunnel study of temperature flow close to regularly arrayed rough surfaces, Boundary Layer Meteorol., 18, 373-397, 1980 .

Sä, L. D. A., Y. Viswanadham, and A. 0. Manz1, Energy flux partitioning over the Amazon forest, Theor. App1. C1imatol., 39, 1-16, 1988 .

Sellers, P. J., W. J. Shuttleworth, J. L. Dorman, A. Dalcher, and J. M. Roberts, Calibrating the simple biosphere model for Amazonian tropical forest using field and remote sensing data, 1 , Average calibration with field data, J. Appl. Meteorol., 28, 727-759, 1989.

Shuttleworth, W. J., Evaporation from Amazonian rain forest, Proc. R. Soc. London. Ser. B 233, 321-346, 1988a.

Shuttleworth, W. J., Corrections for the effect of background concentrations change and sensor drift in real-time eddy correlation systems, Boundary Layer Meteorol., 42, 167-180, 1988b.

Shuttleworth, W. J., and I. R. Calder, Has the Priestley-Taylor equation any relevance to forest evaporation?, J. Appl. Meteorol., 18, 639-646, 1979.

Shuttleworth, W. J., D. D. McNeil, and C. J. Moore, A switched continuous-wave sonic anemometer for measuring surface heat fluxes, Boundary Layer Meteor., 23, 425-448, 1982.

Shuttleworth, W. J., J. H. C. Gash, C. R. Lloyd, C. J. Moore, J. Roberts, A. 0. Marques Filho, G. F. Fisch, V. P. Silva Filho, M. N. G. Ribeiro, L. C. B. Molion, C. A. Nobre, L. D. A. Sä, 0. M. R. Cabral, S. R. Patel, and J. C. Moraes, Eddy correlation measurements of energy partition for Amazonian forest, Q. J. R. Meteorol. Soc., 110, 1143-1162, 1984a.

Shuttleworth, W. J., J.H. C. Gash, C. R. Lloyd, C. J. Moore, J. Roberts, A. O. Marques Filho, G. F. Fisch, V. P. Silva Filho, M. N. G. Ribeiro, L. C. B. Molion, C. A. Nobre, L. D. A. Sá, O. M. R. Cabral, S. R. Patel, and J. C. Moraes, Observations of radiation exchange above and below Amazonian forest, Q. J. R. Meteoro1. Soc., 110, 1163-1169, 1984b.

Shuttleworth, W. J., J. H. C. Gash, C. R. Lloyd, D. D. McNeil, C. J. Moore, and J. W. Wallace, An integrated micrometeorological system for 
evaporation measurement, Agric. For. Meteorol., 43, 295-317, 1988 .

Spittlehouse, D. L., and T. A. Black, Evaluation of the Bowen ratio/energy balance method for determining forest evapotranspiration, Atmos. Oceans., 18, 98-116, 1980.

Stewart, J. B., and A. S. Thom, Energy budgets in pine forest, Q. J. R. Meteoro1. Soc., 99, $154-170,1973$.

Takeuchi, M., The structure of Amazonian vegetation, II, Tropical rain forest, J. Fac. Sci. Tokyo Univ. Sect. III Botany, $8(\overline{3})$, $1-26,1961$.

Taylor, G. I., The transport of vorticity and heat through fluids in turbulent motion, Proc. R. Soc. London, Ser. A, 135, 685-705, 1932.

Thom, A. S., Momentum, mass and heat and exchange of plant communities, in Vegetation and the Atmosphere, vol. I, edited by J. L. Monteith, Pp. 57-109, Academic, San Diego, Calif., 1975.

Thom, A. S., J. B. Stewart, H. R. Oliver, and J. H. Gash, Comparison of aerodynamic and energy budget estimates of fluxes over a pine forest, Q. J. R. Meteorol. Soc., 97, 414-428, 1975.

Viswanadham, Y., Examination of the empirical flux-profile models in the atmospheric surface boundary layer, Boundary Layer Meteorol., 22, $61-77,1982$.

Viswanadham, Y., and R. G. B. André, Energy balance of soybeans grown in Brazil, Arch. Meteorol. Geophys. Bioclimatol., Ser. B, 33, 141-157, 1983.

Viswanadham, Y., R. G. B. Andrē, L. D. A. Sä, A. 0. Manzi, and V. P. Silva Filho, Componentes do balanço de radiação acima da copa da Floresta Amazōnica (Terceira campanha de coleta de dados), Res. Rep. INPE-4195-PRE/1079, 43 pp., Inst. de Pesquisas Espaciais, São Josè dos Campos, Brazil, June $1987 a$.

Viswanadham, Y., L. D. A. Sá, V. P. Silva Filho, and $A$. 0. Manzi, Ratios of eddy transfer coefficients over the Amazon forest, Forest Hydrology and Watershed Management, IAHS, Pub1. 167, 365-373, 1987b.

Viswanadham, Y., V. P. Silva Filho, A. 0. Manzi, and L. D. A. Sā, Analysis of diabatic wind and temperature profiles over the Amazonian forest, Atmospheric Deposition, IAHS, Publ. $179,281-288,1989$.

Webb, E. K., Profile relationships: The log-linear range and extension to strong stability, Q. J. R. Meteorol. Soc., 96, 67-90, 1970.

Yaglom, A. M., Comments on wind and temperature flux-profile relationships, Boundary Layer Meteoro1., 11, 89-102, 1977.

R. G. B. André, Universidade Estadual Paulista, Jaboticabal, São Paulo, Brazil. R. C. dos Santos, A. O. Manzi, L. C. B. Molion, J. L. M. Nogueira, L. D. A. Sä, V. P. Silva Filho, and Y. Viswanadham, Instituto de Pesquisas Espaciais, Secretaria Especial de Ciencia e Tecnologia da Presidencia da República, São José dos Campos, São Paulo, Brazil.

(Received May 5, 1989;

revised March 8, 1990; accepted March 8, 1990.) 